\title{
BILINGUAL RESOURCE CENTERS AND FEDERAL FUNDING
}

\section{Emilio De Torre and Bernard Fradkin, Queens College}

The Bilingual Education Act, Title VII, awarded $\$ 68,000,000$ to Local Education Agencies (LEA) for use in school year 1974-75. Similar funds will be available on a competitive basis for fiscal year 1976. Monies allocated in 1974-75 supported 383 classroom demonstration projects nationwide in forty-two languages in five material centers. Institutions of higher education were generally excluded since the major focus of the program was to meet the direct needs of children 3 to 18 years. old from environments where the dominant language was other than English. The route to be followed by colleges and universities seeking funding was through a companion proposal piggy-backing a solicitation for monies by a local educational agency. Grants to higher education, therefore, could not be submitted directly without district support and direct involvement. In this way, the local educational agency was principally responsible for the project and its funds.

The procedures to acquire funds outlined by the division of bilingual education proved difficult and did not promote the overall objectives of the Bilingual Education Act for cooperation between local school districts and institutions of higher learning. Specifically the following problems were evident:

1. College grant objectives had to be compromised, thereby watering down the overall program strength.

2. The local educational agencies frequently feared eventual takeover of any joint project by higher education.

3. College and universities often could not submit a joint proposal with local agencies because the latter's size or geographic complexity made it impossible to apply the grant's program or objectives (the local educational agency might be an entire school district.) So too, multi-district submissions were really not possible.

4. The schedules for application or even the administration of funds, in the event of a received grant, were complicated by the different scholastic calendars, review procedures, and personnel that had to be considered by the joint participants.

The government should have foreseen and removed those difficulties before demanding joint proposals. All problems should have given way to the preparation of qualified personnel, without whom no viable program can be established.

The need for well-prepared bilingual/bicultural instructors had been emphasized by a grant from the U.S. Office of Education to the Center for Applied Linguistics! (under Title V, EPDA) to support a conference that outlined criteria and responsibilities of instructional personnel and estab- 
lished guidelines for their preparation and certification. The guidelines pointed out that, to be competent, a bilingual/bicultural instructor should be aware of educational technology and should be versed in the use of media so as to achieve the full academic potential of the student, the program, and the instructor himself as optimally functioning parts of a single effective unit.

The bilingual instructor is a relatively new person on the educational scene, and he deals with students who are not so clearly defined and placed as the monolingual/monocultural students. ${ }^{2}$ Add to this the scarcity of instructional materials and we find an area in education in need of much help.

The relative newness of the bilingual programs and the corresponding instructors, as well as the heterogeneous student participants, emphasize the need for audiovisual materials aimed specifically at students in specific bilingual/bicultural programs. It is as educationally unsound to adopt imported materials that have been prepared for a monolingual/monocultural student as it is to leave a non-English dominant student in an English dominant program. So too, it can be just as damaging, culturally at least if not linguistically, to employ bilingual materials developed for another ethnic group. The generic term "bilingual" does not give all groups a sufficiently common basis of language or culture to justify the use of each other's materials so freely as some would have us believe. ${ }^{3}$

A resource center outfitted for bilingual/bicultural education can supply many supportive measures to a program that might otherwise fail. Instructional resources can help to individualize instruction; to multiply the time available to teachers, to identify the student levels, to test criteria and student attainment; in short, they can provide all of those things which are available to the monolingual/monocultural programs but which are not readily available in bilingual/bicultural areas. In order to facilitate the mainstreaming of this new target population as is the aim of the Bilingual Education Act, it is necessary to set up instructional resources with the objective and criteria of the bilingual/bicultural programs specifically in mind and within the institutions of higher education which are preparing the personnel for these programs. Only through the integration of the techniques of educational technology can the traditional academic information be applied in order to reach students who might well be considered deprived culturally and linguistically in two cultures and languages. Given the high success of visual literacy among monolingual/monocultural student population ${ }^{5}$ we should be able to project the same successes in bilingual/bicultural programs provided that the resource centers and instructors work together towards a common objective. This joint effort requires offering the instructors the opportunity to work with educational technologists or to use educational technology on their own in the preparation of materials. 
To date, most bilingual teacher education programs have dealt with the preparation of personnel in cultural awareness, in second language methodology and, at times, in materials acquisition. ${ }^{6}$ A methodology course in bilingual/bicultural education involving objectives, presentation, testing, etc., is too often absent from the curriculum. It is needless to say that if such a basic course is often overlooked, the role of instructional media is not even mentioned.

Media as an educational tool for reaching and instructing the bilingual/ bicultural student is a successful and acceptable part of our current sociological thrust, but it seems painfully limited to those grants which can prepare "public" successes, as has been the case with Villa Alegre, Carrascolendas and an occasional Hispanic portion on Sesame Street, as opposed to teacher prepared/teacher used resources. These programs are aimed at the Hispanic communities as a whole and are not necessarily acceptable either linguistically nor culturally to all of its many components. The language and culture of the primarily Mexican-Americans of Villa Alegre or Carrascolendas are not essentially those of Puerto Rican-Americans of the New York area, nor are the three preceding groups linguistically or culturally like the Cuban-Americans in Florida.

Then again, although it would seem that the Government favors, at least publically, the Hispanic American population insofar as bilingual/ bicultural education is concerned, such is not, in fact, the case. The law is quite clear in having as its objective the education of all non-English dominant students. Nonetheless, the government's major bilingual/ bicultural grants seem directed toward the preparation of materials for Hispanics, ${ }^{7}$ a fact perhaps due to a government decision to do as much as possible with what funds are available, for what is probably its largest ethnic component in need of special education projects. ${ }^{8}$ Whereas, if the government had given assistance to higher education institutions with ongoing programs in education, languages, linguistics, anthropology, etc. and having instructional development or resource centers or learning laboratories they could have produced, in cooperation with local educational agencies, a larger variety and quantity of materials than has been produced via joint proposals or proposals to local education agencies alone. In turn, instructional packages might be used by a better-trained local personnel with greater success - due to the immediate ethnic acceptability of the materials by the ethnic groups in question - while at the same time meeting the instructional objectives and criteria of the very personnel who, as the end-users, were also the prime creators.

Important allowances for change which now include institutions of higher education and thus, learning laboratories permit bilingual education proposal initiatives to be worthwhile. One of the major thrusts of bilingual education will be the training of teachers to instruct in languages 
other than English. Teachers will be able to use the students' dominant language to support learning development. The key words denoting the new direction as explained by Ms. Peggy Kingsbury, a Queens College Grants Officer, are "Capacity Building." Simply speaking, capacity building means training bilingual educators in order to invalidate bilingual education solely as a student process and thus, legitimizing its presence in teacher preparation programs at higher education agencies. It means formal rather than on-the-job training. The role of an institution learning laboratory in co-authoring a proposal for bilingual education has several advantages:

a. The learning laboratory staff represents a source of instructional development and expertise in the organization and production of programs for education.

b. Programs based in learning laboratories have a foundation that is part of an ongoing and established area of instructional support to carry the objectives of the grant beyond the period of funding.

c. Learning laboratories are often setting for evaluation of instructional processes and provide support for the collection of data and validation of instructional pedagogy.

d. Learning laboratories have existing equipment which requires minimal expenditure for remote resource dissemination. This minimizes the expenditures for materials and equipment at the local agency levels.

e. Development of a bilingual education program can further the interdisciplinary nature of learning labs by associating many departments in a coordinated project.

Although the new direction and possibilities seem extremely promising there are certain limitations that must be considered in applying for grants under the Bilingual Education Act. These criteria are outlined clearly and must be carried through in proposals written for 1976. Among these criteria are the following directives:

1. Programs should be interdisciplinary.

2. Programs must be with an established school of education.

3. Programs should offer field-based experience.

4. Staff competencies are essential.

5. Programs must be solidly founded in the philosophy of bilingual/ bicultural education.

Further elaboration of each of these specified areas can be found in reading the Federal Register, Volume 40, No. 122, Tuesday, July 24, 175 where the Office of Education, Department of Health, Education and Welfare explains the interim regulations concerning the Bilingual Education Act. The Division of Bilingual Education does not seem interested in the 
following areas for the 1976 funding period: ethnic studies, English as a second language, linguistics, and foreign language departments. Interest lies specifically in teacher preparation. There also seems to be a priority aimed at the development of resource centers which could be used in the same context as learning laboratories which operate to assist teachers in the development and preparation of materials (see No. 123.12, Authorized Activities, page 26517 of the Federal Register). The Bilingual Education Act seeks to support regional resource centers, materials development centers and dissemination assessment centers. If funding is approved and passed by Congress it is expected that the fiscal year of 1976 will yield approximately $\$ 100,000,000$ in grants. Of course, the funds are not assured for they are contingent upon Congressional and Executive action. Rules, regulations and applications will be available well in advance of the due date for proposals. Technical assistance is also available for the writing of Bilingual Grants by contacting the Office of Bilingual Education in Washington. The address and telephone number of their location is: Office of Education, 7th and D Street SW, Washington, D.C. 20202. Phone: 202-245-9576.

\section{FOOTNOTES}

1Center for Applied Linguistics, Guidelines for the Preparation and Certification of Teachers of Bilingual/Bicultural Education. (Nov., 1974)

2von Maltitz, Frances, Living and Learning in Two Languages. McGraw-Hill Book Co. (New York, 1975)

3Examples of currently available bilingual materials are:

a) New York City Board of Education, Bilingual Audiovisual Materials. (May, 1973) ED 084919

b) San Diego City Schools, Materiales en marcha.

c) Dissemination Center for Bilingual Bicultural Education, Cartel: Annotated Btbliography of Bllingual Bicultural Materials.

4Scanlon, Robert G. \& Joann Weinberger, Complled Blbliography on Improving Productivity of School Systems Through Educational Technology. (Philadelphia, Pa. Nov. '73) ED 086241.

SDebes, John L. "Visual Literacy Strides Cited by Kodak Experts". The Journal: Technological Horizons in Educatlon. (March, 1975)

6joramillo, Mari-Luci, "Ongoing Teacher Preparation". Today's Education (Jan-Feb, 1975) p. 74-77.

7Pena, Albar A., "Bilingual Education: An Overview" Today's Education (Jan-Feb, 1975) p. 71-73.

8NEA Government Relations, "Action by the 93rd Congress", Todays Education (Jan-Feb, 1975) p. 81-82. 